\title{
KNOWLEDGE, ATTITUDE AND PRACTICE OF HAND HYGIENE AMONG HEALTH CARE WORKERS IN KARACHI
}

\author{
Imran Ahmed ${ }^{1}$, Asif Khan ${ }^{2}$, Abdul Ahad Sohail ${ }^{3}$ and Mujeeb-u-Rehman ${ }^{4}$
}

${ }^{1}$ Assisstant Professor, Ziauddin University Karachi

${ }^{2,3,4}$ Student Ziauddin University Karachi

Correspondence:Imran Ahmed, Cell: 0333-2485287,Email:dr_imran_ahmedi@hotmail.com

\begin{abstract}
Background: Hospital acquired infections (HAls) are one of the most common problems encountered in health care. It is a major cause of concern for hospitals throughout the world.

Methods: The study design was cross sectional and data was obtained from health care workers currently employed in hospitals. We selected tertiary care hospitals by convenient sampling technique. Data were analyzed through SPSS version 20.

Results: A total of 330 health care workers were included in the study out of which $54.4 \%$ (180) were males and the rest $45.4 \%$ (150) were females. When the participants were asked of the minimum time required for alcohol based hand rub to eradicate the microorganisms, only $42 \%$ (138) were able to correctly answer that it takes 20 seconds.

Conclusion: Our study identified considerable gaps in knowledge and practice in some key areas regarding hand hygiene which need re-emphasis through regular training sessions aim at keeping abreast with standard protocols of hand hygiene.
\end{abstract}

Keywords: Health care workers, hand hygiene, health care providers.

\section{Introduction}

Hospital acquired infections (HAls) are one of the most common problems encountered in health care (1). It is a major cause of concern for hospitals throughout the world. (2).A study showed that at least $5-15 \%$ patients acquire the infections during their stay in the hospital (1).Another study conducted in Europe and in lowmiddle income countries showed the prevalence in Europe to be about $5.7 \%$ and higher in low-middleincome countries of about $16 \%$. $(1,2)$. These infections acquired during the stay of the patient in the hospital causes a number of disabilities, and a high morbidity rate, which is a cause of increased burden on the health care costs on the patient and health services due to prolonged stay in the hospital and additional medications.(2). A study conducted in Europe and United States showed that the annual cost incurred due to HAls ranges from 13-24billion dollars in Europe and around 6.5 billion dollars in United States. About $50 \%$ of the hospital acquired infections occurs from the hands of health care providers (3). And at least $20 \%$ of these acquired infections are preventable by simple measures of hand hygiene (1), which is the most efficient and costeffective method for infection control. (3). Any action of cleaning hands and removal of the microorganisms from hands using soap and water or alcohol and antiseptic hand rub is acknowledged as hand hygiene (3).
According to several researches, alcohol based hand rubs are more effective than hand washing with soap and water for removal of pathogenic microorganisms, and is tolerated well by the skin $(1,2,4,5)$. In alcohol based hand rubs, gels are tolerated well by the skin as compared to the liquid formulations (5).

Although the large number of recent studies that has provided us with increased data regarding hospital acquired infections and hand hygiene, the compliance of hand hygiene in developing countries is still very low (3). A study conducted in Ethiopia (underdeveloped country) showed that the compliance of hand hygiene in health care workers is $5-89 \%$ (average $38.7 \%$ ) which is unacceptably low(3).A study in China found that compliance of hand hygiene in health care workers is about $30-75 \%$ (6). A study conducted in National Taiwan university hospital found that only $16.6 \%$ of health care workers perform hand hygiene (7).

We found out that very few studies has been conducted on this subject in Pakistan, in fact we could find only one study conducted previously in Pakistan(Karachi), whose finding showed that only $4.7 \%$ of the respondents clean their hands before direct contact with the patients. (8). And only $17 \%$ of the physician stated that they were aware of the WHO guidelines regarding hand hygiene.(8). 


\section{Methodology}

This cross sectional study was conducted in tertiary care hospitals in the city of Karachi (JPMC, Civil Hospital and Ziauddin Hospital). All health care workers working in these hospitals were approached. Their knowledge, attitude and practices regarding hand hygiene were evaluated through a self-administered questionnaire. Sampling technique for our study was convenience sampling technique. Total number of participants included in the study were 330 with a confidence interval of $95 \%$ and standard deviation of $5 \% .20 \%$ wastage was also added to the sample size. Sample size was calculated using the formula $n=z 2 p(1-p) / d 2$. The participants included in the study were health care workers working in these hospitals which included all doctors, nurses, and technicians. There were no age and gender restrictions. Excluded from the study were those who had language barrier, those not willing to consent, and those absent at the time of data collection. Data was collected from the participants through selfadministered questionnaire. The questionnaire is adapted from WHO Hand Hygiene Knowledge Questionnaire for Health-Care Workers. All the questionnaires were filled by participants in front of the primary researchers and they were not allowed to use any external source of knowledge for completing the questionnaire. Data was analyzed on SPSS version 20. All qualitative variables were presented as frequency and percentages. Chi-square test was used to find association between categorical variables and a p-value less than 0.05 was considered as significant. Informed consent taken from participants before being included in the study. All information gathered from the participants was kept confidential. Names of the participants will not be asked; instead each questionnaire marked by a serial number.

\section{Results}

A total of 330 health care workers were included in the study in which their knowledge was assessed regarding the use of alcohol based hand rub and how it prevents the spread of pathogenic microorganisms from one patient to another. In our survey, out of total participants, $54.4 \%$ (180) were males and the rest $45.4 \%$ (150) were females (Table 1). That included $52 \%$ (172) doctors and $48 \%$ (158) nurse/staff members.
Table 1: Demographic Characteristics of the Participants

\begin{tabular}{|c|c|c|c|c|}
\hline Variable & Male & Female & OR M/F* & Total \\
\hline $\begin{array}{c}\text { No. of } \\
\text { Participants }\end{array}$ & 180 & 150 & 1.2 & 330 \\
\hline $\begin{array}{l}\text { Percentage of } \\
\text { Participants }\end{array}$ & 54.4 & 45.4 & - & 100 \\
\hline \multicolumn{5}{|c|}{ Training Session } \\
\hline \multicolumn{2}{|c|}{ Variable } & Doctors & Nurse/staff & $\begin{array}{c}\text { Total } \\
\text { participant } \\
\mathbf{n}=\mathbf{3 3 0} \\
\end{array}$ \\
\hline \multicolumn{2}{|l|}{ Trained } & 57 & 132 & $189(57.30)$ \\
\hline \multicolumn{2}{|l|}{ Not Trained } & 115 & 26 & $141(42.7 \%)$ \\
\hline \multicolumn{5}{|c|}{ Mode \& Source Of Health care Associated Infections (HAI) } \\
\hline \multicolumn{2}{|c|}{ Variable } & Doctors & Nurse/staff & $\begin{array}{c}\text { Total } \\
\text { participant } \mathbf{n} \\
=\mathbf{3 3 0}\end{array}$ \\
\hline $\begin{array}{l}\text { Main route of cross- } \\
\text { transmission of germs by }\end{array}$ & ns by & 171 & 100 & $271(82 \%)$ \\
\hline \multicolumn{2}{|c|}{$\begin{array}{l}\text { Frequent source for HAI are the } \\
\text { germs on or within patients }\end{array}$} & 121 & 126 & $247(75 \%)$ \\
\hline
\end{tabular}

*OR M/F = Odds ratio Male to female

According to the analysis $57.3 \%$ (189 out of 330 ) had received formal training in hand hygiene/ washing in the last 3 years as shown below.

KNOWLEDGE: In the study, participants were asked of the minimum time required for $A B H R$ to kill the microorganisms. The results are shown in the pie chart below (figure 1):

\section{Percentage of participants}

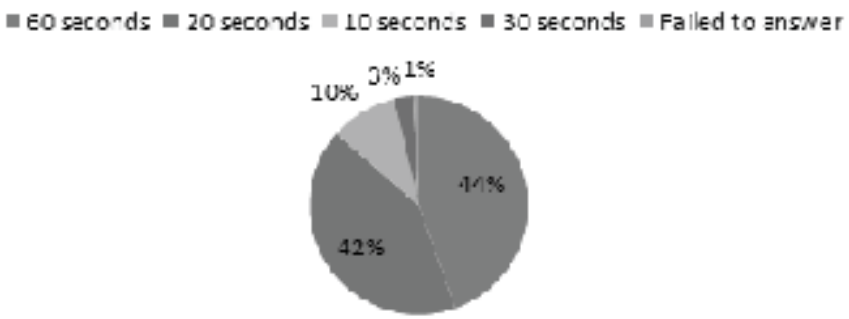

Figure 1. Percentage of the participants who knew the minimum time required for $A B H R$ to kill the microorganisms

Most $(82 \%)$ participants $(n=271)$ correctly identified the main route of cross-transmission of potentially harmful germs. While $75 \%$ participants $(n=247)$ identified that germs already present on or within patients are the frequent source of harmful germs responsible for health care-associated infections ( $\mathrm{HAI}$ ) as shown in table.

ATTITUDE: Then in a series of questions, hand rubbing with alcohol based hand rub was compared with hand washing with soap and water. When asked whether hand rubbing is more rapid for hand cleansing than hand washing, $83.6 \%$ (276) of the participants felt that it was true. Also, $88.2 \%$ (291) of participants answered that hand rubbing causes more skin dryness than hand washing with soap and water. When asked which of the two is more affective against the microorganisms, $62.7 \%$ (207) felt that hand rubbing is more effective. Finally, 
$76.4 \%$ (252) of the participants believed that the recommendation is to perform hand rubbing and then hand washing in a sequence.

Table 2: Attitude of the Health Care Staff

\begin{tabular}{|c|c|c|c|}
\hline Variable & Doctors & Nurse/staff & $\begin{array}{c}\text { Total participant n } \\
=\mathbf{3 3 0}\end{array}$ \\
\hline $\begin{array}{c}\text { Handrubbing rapid for } \\
\text { hand cleansing than } \\
\text { handwashing }\end{array}$ & 153 & 123 & $276(83.6 \%)$ \\
\hline $\begin{array}{c}\text { Handrubbing causes } \\
\text { skin dryness more } \\
\text { than handwashing }\end{array}$ & 140 & 151 & $291(88.2 \%)$ \\
\hline $\begin{array}{c}\text { Handrubbing is more } \\
\text { effective against } \\
\text { germs than } \\
\text { handwashing }\end{array}$ & 129 & 78 & $207(62.7 \%)$ \\
\hline $\begin{array}{c}\text { Handwashing and } \\
\text { handrubbing to be } \\
\text { performed in } \\
\text { sequence }\end{array}$ & 113 & 139 & $252(76.4 \%)$ \\
\hline
\end{tabular}

Then the participants were given a list of options and they had to answer whether each of them is associated with increased likelihood of colonization of hands with pathogenic microorganisms. Results are shown in the chart below (figure 2):

\section{Percentage of participants.}

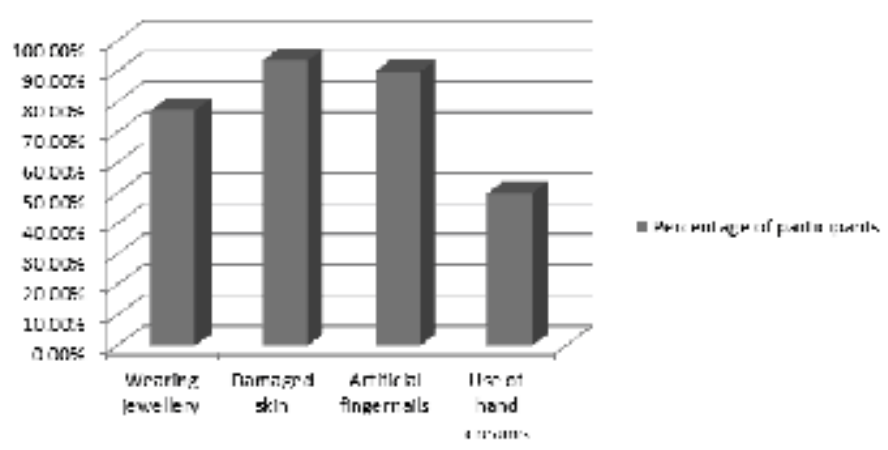

Figure 2. Percentage of the participants knowing source of colonization of microorganisms.

PRACTICES: After that the health care workers were given a list of situations and for each of them they had to choose whether they would do hand rubbing with alcohol based hand rub, handwashing with soap and water or nothing. $0.9 \%$ (3) participants failed to answer this question. The results are shown in the table 3 below:

\section{Table 3: Practices of Health Care workers}

\begin{tabular}{|l|c|c|c|}
\hline Variable & Rubbing \% & Washing \% & None \\
\hline Before palpation of the abdomen. & 26.4 & 69.1 & 3.6 \\
\hline Before giving an injection. & 22.7 & 72.7 & 3.6 \\
\hline After emptying a bedpan. & 9.1 & 87.3 & 2.7 \\
\hline After removing examination gloves. & 12.7 & 85.5 & 0.9 \\
\hline After making a patient's bed. & 11.8 & 87.3 & 0 \\
\hline After visible exposure to blood & 23.6 & 75.5 & 0 \\
\hline
\end{tabular}

\section{Discussion}

Health care associated infections (HAls) are a major cause of morbidity and mortality among patients admitted to the hospitals, be it wards or intensive care units. (6) The rates are higher in both developed and third world countries. Several recent researches have demonstrated that good hand hygiene of health care workers hands is the single most effective way to decrease HAls $(7,9)$. According to latest World Health Organization (WHO) and Centres for Disease Control and Prevention (CDC) guidelines, hand rubbing with alcohol based hand rub has replaced the conventional hand washing with soap and water $(10,11)$. In our survey, when the knowledge of health care workers was assessed regarding the differences between hand rubbing and hand washing, they demonstrated good knowledge of $\mathrm{ABHR}$ with $83.6 \%$ correctly answering that hand rubbing is more rapid for hand cleansing than hand washing and $62.7 \%$ correctly answering that hand rubbing is more effective against pathogenic microorganisms. These results were similar to a research conducted in a university hospital in Taiwan which also determined that conventional hand washing takes longer time and is less effective against infective organisms.(12)

Although many of our participants were aware of the fact that the alcohol based hand rub is rapid acting, unfortunately, they were not aware of the proper timing for which to use it to be most effective. Only $42 \%$ of the total participants correctly answered it to be 20 seconds out of which $26.4 \%$ of the total had formal training regarding hand hygiene in the last three years. This is in accordance to the WHO recommendations which says that hand rubbing should be done for at least $20-30$ seconds while hand washing needs to be done for at least 40 - 60 seconds. This shows that more awareness needs to be created and educational programs needs to be organized frequently to train health care workers regarding proper hand hygiene in accordance to the latest WHO guidelines. In present study most of the participants $(82 \%)$ correctly identified that main source of cross-transmission of harmful germs in health care facility as when the health care workers do not clean their hands during work. Three forth of total participants have core knowledge that germs that are already present on or within patients are frequent sources of harmful germs responsible for HAI. Similar result was found in a research study conducted in Addis Ababa, Ethiopia in 2013 (13).

In our study a large number of the participants felt that hand rubbing with $A B H R$ is more associated with skin dryness and irritation than hand washing. These results are similar to another study conducted in Karachi, Pakistan which also determined that most of its participants felt that it is more associated with skin irritation so much so that it had lead to poor compliance with in their health care workers (8). On the contrary the two studies that were conducted in Switzerland and Taiwan found that hand rubbing is less associated with skin dryness and irritation than with conventional hand washing with antimicrobial soap and water $(5,12)$. In our study the health care workers are well informed regarding what causes more colonization of bacteria on the hands of health care worker. $90.9 \%$ felt that the 
artificial nails cause hands to become more prone to colonization while $94.5 \%$ felt that damaged skin increase the chances of colonization with microorganisms. A study conducted in Nigeria demonstrated similar results with only $7.6 \%$ of health care workers using artificial nails showing they were aware of the fact that artificial nails or long nails allow greater colonization of the bacteria under it and also make cleaning difficult. (10). This research also found that one of the causes of damaged skin was using brush for cleaning when hand washing with anti-microbial soap and water and therefore leading to greater colonization with bacteria and therefore concluding that hand rubbing with $A B H R$ is more effective than hand washing. (10)

According to $\mathrm{WHO}$ guidelines, "my five moments of hand hygiene", a health care worker needs to perform hand hygiene before and after most situations in his or her daily practice. $(14,15)$. According to WHO guidelines many countries and hospitals as part of quality assurance regularly audit hand hygiene. (16) Unfortunately, most of the health care workers in our study sample demonstrated poor knowledge of the fact that when to use hand rub and when to do hand washing for example $85.5 \%$ felt that hand washing should be performed after removing the gloves while WHO guidelines and a research conducted in Netherlands clearly states hand rubbing needs to be performed. (15). A study conducted on community health care workers showed similar results with $95.5 \%$ performing hand washing after removal of gloves. (10). The only scenario in which $75.5 \%$ of the health care workers answered correctly was that hand washing needs to be performed after visible exposure to blood or secretions. This is correct according to both WHO and CDC guidelines. They recommend hand rubbing in all situations unless there is visible exposure to any of the body secretions or ABHR is unavailable. (10). A study conducted by Doran JA et al in Chicago regarding understanding of hand hygiene among third and fourth year medical students concluded that students demonstrated the best knowledge and worst practices among all health care workers regarding the hand hygiene (17). More studies need to be conducted to determine the knowledge and practices of health care workers working in different departments and different settings in a hospital for example intensive care units, operation theatres, and wards. Also more studies need to be performed which determines the overall compliance of hand hygiene in developing countries and the gold standard in under observation by trained auditors who can observe a health care worker in all 5 moments of hand hygiene. (18).

\section{Conclusion}

The present study identified gaps in hand hygiene knowledge and therefore practices among health care workers. Therefore our study highlights the importance of regular training sessions on health hygiene for health care workers and so frequent workshops and seminars need to be conducted. Also posting reminders throughout the hospitals and handing out written instructions on how to properly perform hand hygiene to both the health care workers and visitors to the hospital will help in improving the knowledge and therefore practices of hand hygiene among health care workers which directly leads to better patient care and improved health care. Further studies are recommended to observe variations in knowledge, and practices of hand hygiene among doctors, nurses, technicians and rest of the health care staff.

\section{References}

1. DegliAtti ML, Tozzi AE, Ciliento G, Pomponi M, Rinaldi S, Raponi M. Healthcare workers' and parents' perceptions of measures for improving adherence to hand-hygiene. BMC public health. 2011 Jun 13;11(1):466.

2. Lindsjö C, Sharma M, Mahadik VK, Sharma S, Lundborg CS, Pathak A. Surgical site infections, occurrence, and risk factors, before and after an alcohol-based handrub intervention in a general surgical department in a rural hospital in Ujjain, India. American journal of infection control. 2015 Nov 1;43(11):1184-9.

3. Abdella NM, Tefera MA, Eredie AE, Landers TF, Malefia YD, Alene KA. Hand hygiene compliance and associated factors among health care providers in Gondar University Hospital, Gondar, North West Ethiopia. BMC Public Health. 2014 Jan 30;14(1):96.

4. Mody L, Saint S, Kaufman SR, Kowalski C, Krein SL. Adoption of alcohol-based handrub by United States hospitals: a national survey. Infection Control \& Hospital Epidemiology. 2008 Dec 1;29(12):1177-80.

5. Traore O, Hugonnet S, Lübbe J, Griffiths W, Pittet D. Liquid versus gel handrub formulation: a prospective intervention study. Critical care. 2007 May 3;11(3):R52.

6. Mu X, Xu Y, Yang T, Zhang J, Wang C, Liu W, Chen J, Tang L, Yang H. Improving hand hygiene compliance among healthcare workers: an intervention study in a Hospital in Guizhou Province, China. Brazilian Journal of Infectious Diseases. 2016 Oct;20(5):413-8.

7. Chen YC, Sheng WH, Wang JT, Chang SC, Lin HC, Tien KL, Hsu LY, Tsai KS. Effectiveness and limitations of hand hygiene promotion on decreasing healthcare-associated infections. PLoS One. 2011 Nov 16;6(11):e27163.

8. Anwar MA, Rabbi S, Masroor M, Majeed F, Andrades M, Baqi S. Self-reported practices of hand hygiene among the trainees of a teaching hospital in a resource limited country. JPMA. The Journal of the Pakistan Medical Association. 2009 Sep;59(9):631.

9. Kapil R, Bhavsar HK, Madan M. Hand hygiene in reducing transient flora on the hands of 
healthcare workers: an educational intervention. Indian journal of medical microbiology. $2015 \mathrm{Jan}$ 1;33(1):125.

10. Braimoh OB, Udeabor SE. Hand hygiene practices among community health officers in Rivers State, Nigeria. African health sciences. 2013;13(2):507-11.

11. Saramma PP, Krishnakumar K, Dash PK, Sarma PS. Alcohol-based hand rub and ventilator-associated pneumonia after elective neurosurgery: An interventional study. Indian journal of critical care medicine: peer-reviewed, official publication of Indian Society of Critical Care Medicine. 2011 Oct;15(4):203.

12. Shen NJ, Pan SC, Sheng $\mathrm{WH}$, Tien KL, Chen $\mathrm{ML}$, Chang SC, Chen YC. Comparative antimicrobial efficacy of alcohol-based hand rub and conventional surgical scrub in a medical center. Journal of Microbiology, Immunology and Infection. 2015 Jun 30;48(3):322-8.

13. Tenna A, Stenehjem EA, Margoles L, Kacha E, Blumberg HM, Kempker RR. Infection Control Knowledge, Attitudes, and Practices among Healthcare Workers in Addis Ababa, Ethiopia. Infection control and hospital epidemiology?: the official journal of the Society of Hospital Epidemiologists of America. 2013;34(12):12891296. doi:10.1086/673979.

14. Kirk J, Kendall A, Marx JF, Pincock T, Young E, Hughes JM, Landers T. Point of care hand hygiene-where's the rub? A survey of US and Canadian health care workers' knowledge, attitudes, and practices. American journal of infection control. 2016 Oct 1;44(10):1095-101.

15. Helder OK, van Goudoever JB, Hop WC, Brug J, Kornelisse RF. Hand disinfection in a neonatal intensive care unit: continuous electronic monitoring over a one-year period. BMC infectious diseases. 2012 Oct 8;12(1):248.

16. Gould DJ, Creedon S, Jeanes A, Drey NS, Chudleigh J, Moralejo D. Impact of observing hand hygiene in practice and research: a methodological reconsideration. Journal of Hospital Infection. 2017 Feb 1;95(2):169-74.

17. Doran JA, Parada JP. Myths and Realities Regarding Medical Students' Hand Hygiene Understanding and Practices. American Journal of Infection Control. 2017 Jun 1;45(6):S61.

18. Boyce JM. Electronic monitoring in combination with direct observation as a means to significantly improve hand hygiene compliance. American journal of infection control. 2017 May 1;45(5):528-35.--- 